\title{
Tax Planning Melalui Penerapan Zakat Sebagai Upaya Meminimalisir Beban Pajak Badan (Studi Kasus Pada PT. Wonojati Wijoyo, Kediri)
}

\author{
Oleh: \\ Puji Rahayu, SE., MM \\ Dosen Akuntansi, Universitas Islam Kadiri, Kediri \\ Email : puji.ak.uniska@gmail.com
}

\begin{abstract}
ABSTRAK
Penerapan tax planning melalui tax law dengan memanfaatkan celah dalam peraturan perpajakan salah satunya yang dikecualikan dari objek pajak yaitu pembayaran zakat pada badan amil zakat atau lembaga amil zakat yang dibentuk atau disahkan oleh pemerintah. Zakat merupakan bagian dari rukun islam yaitu rukun yang ke tiga. Bagi umat islam hukum zakat itu wajib dikerjakan. Manajemen perusahaan sudah melakukan perencanaan pajak dalam meminimalisir beban pajak.Cara yang sudah pernah digunakan oleh perusahaan melalui penyusutan aktiva dan melakukan pendanaan pengadaan barang menggunakan jasa leasing atau sewa guna usaha.Namun perusahaan belum pernah menerapkan pembayaran zakat sebagai penghematan pajak. Tujuan dari penelitian ini untuk mengetahui tax planning melalui penerapan zakat sebagai upaya meminimalisir beban pajak badan.

Jenis data yang digunakan dalam penelitian ini adalah data kualitatif dan kuantitatif. Data dalam penelitian ini yang diambil langsung berupa data tentang struktur organisasi perusahaan, data karyawan, sejarah perusahaan dan sistem perencanaan pajak yang telah diterapkan perusahaan. Tehnik analisis data yang digunakan dalam penelitian ini adalah deskriptif kualitatif dengan menganalisis rekonsiliasi fiskal guna menghitung PPh Badan yang dilakukan perusahaan sebelum menerapkan perencanaan pajak melalui pembayaran zakat, menghitung besarnya zakat, menghitung $\mathrm{PPh}$ Badan setelah menerapkan perencanaan pajak melalui pembayaran zakat, Membandingkan PPh Badan yang terutang sebelum dengan setelah menerapkan perencanaan pajak melalui pembayaran zakat.

Dari hasil penelitian disimpulkan bahwa beban pajak penghasilan yang terutang oleh perusahaan pada tahun 2016 sebelum melakukan penerapan perencanaan pajak melalui pembayaran zakat sebesar Rp 282.355.625,- sedangkan setelah melakukan penerapan zakat sebesar Rp 275.449.750,- selisihnya sebesar Rp 6.905.875,- dan pajak yang terutang sebelum rekonsiliasi fiskal sebesar Rp 275.096.375,-. Terdapat selisih sebesar Rp 353.375,-.sehingga peneliti merekomendasikan agar melakukan penerapan pembayaran zakat kepada badan amil zakat atau lembaga amil zakat yang telah disahkan oleh pemerintah karena telah dilegalkan oleh peraturan perpajakan dan membayar zakat selain mampu membersihkan harta juga merupakan perintah dari Allah SWT yang wajib kita laksanakan sesuai dengan firman-NYA dalam Al Quran.
\end{abstract}

Kata kunci :Tax Planning, Zakat, dan Beban Pajak Badan. 


\begin{abstract}
Implementation of tax planning through tax lawdengan exploiting loopholes in tax regulations one of which is exempted from the tax object is the payment of zakat on the amil zakat or amil zakat institutions established or endorsed by the government. Zakat is part of the pillar of Islam is the third pillar. For the Islamic ummah zakat law it must be done.Manajemen company has done tax planning in minimizing the tax burden.How that has been used by companies through depreciation of assets and financing the procurement of goods using leasing or leasing services.Namun companies have never applied zakat payments As a tax savings. The purpose of this study to know the tax planning through the implementation of zakat as an effort to minimize the agency tax burden.

Types of data used in this study are qualitative and quantitative data. Data in this study are taken directly in the form of data about corporate organizational structure, employee data, company history and tax planning system that has been applied company. The data analysis technique used in this research is qualitative descriptive by analyzing fiscal reconciliation in order to calculate the Corporate Income Tax by applying the company before applying the tax planning through the payment of zakat, calculating the amount of zakat, calculating the Income Tax after applying the tax planning through zakat payment, Comparing the Income Taxes owed before After applying the tax planning through the payment of zakat.

From the research result, it is concluded that the income tax burden payable by the company in 2016 before doing the implementation of tax planning through the payment of zakat amounting to $\mathrm{Rp} 282.355 .625$, - while after implementing the zakat of $\mathrm{Rp} 275.449 .750$, - the difference of $\operatorname{Rp} 6.905 .875$, - And tax payable prior to the fiscal reconciliation of $\mathrm{Rp} 275,096,375$, -. There is a difference of $\mathrm{Rp} 353,375$, - so the researcher recommends to apply zakat payment to amil zalcat or amil zalcat institution which has been legalized by the government because it has been legalized by taxation and paying zakat besides being able to clean the property is also a mandatory command of Allah SWT We carry out according to His word in the Al-Qur'an.
\end{abstract}

Keywords: Tax Planning, Zakat, and Corporate Tax Burden.

\section{PENDAHULUAN}

\section{Latar Belakang}

Indonesia merupakan Negara yang sedang mengepakan sayapnya dalam dunia perekonomian global.Terlihat jelas dari berbagai sektor yang memudahkan segala hal yang berkaitan dengan perkembangan ekonomi global seperti perizinan usaha yang semakin cepat dalam prosesnya, mempermudah investor dalam menginvestasikan dananya ke Indonesia serta peraturan perpajakan yang dibuat sangat efisien, sehingga mempermudah dalam penerapannya.
Pajak merupakan kontribusi terbesar dalam pemasukan Negara. Dari dana tersebut disalurkan melalui berbagai aspek seperti pendidikan, infrastruktur, keamanan, keagamaan dan lain sebagainya. Pajak terbagi menjadi dua jenis yaitu pajak pusat dan pajak daerah. Pajak pusat meliputi : pajak penghasilan, pajak pertambahan nilai, pajak bumi dan bangunan sektor kehutanan, pertambangan dan perkebunan. Sedangkan pajak daerah meliputi : pajak hotel, pajak restaurant, pajak surat tanda kendaraan bermotor, retribusi, serta pajak bumi dan bangunan perkotaan dan pedesaan.

Perencanaan pajak yang dilakukan sesuai dengan peraturan perpajakan yaitu secara 
legal.Tujuan perusahaan melakukan perencanaan pajak untuk meminimalisir agar kewajiban pajak yang ditanggung perusahaan lebih rendah.Strategi yang dapat digunakan dalam melakukan perencanaan pajak (Tax Planning) melalui tax policy, tax law, dan tax administration. Dalam penelitian ini peneliti mencoba melakukan penerapan tax planning melalui tax lawdengan memanfaatkan celah dalam peraturan perpajakan salah satunya yang dikecualikan dari objek pajak yaitu pembayaran zakat pada badan amil zakat atau lembaga amil zakat yang dibentuk atau disahkan oleh pemerintah.

Zakat merupakan bagian dari rukun islam yaitu rukun yang ke tiga. Bagi umat islam hukum zakat itu wajib dikerjakan (bagi yang telah tercukupi haulnya) akan tetapi bila enggan membayar atau melaksanakan kewajiban tersebut lantaran sifat bakhil dan kikir maka zakatnya boleh diambil secara paksa. Allah SAW berfirman dalam Al Qur'an (Surat An Nur ayat 24-25 ) :

"Dan dirikanlah sholat dan tunaikanlah zakat dan taatlah kepada Rosul, supaya kamu diberi rahmat."

Gurning dan Ritonga (2014) dalam jurnalnya mengungkapkan secara umum zakat terbagi menjadi dua yaitu zakat jiwa (zakat fitrah) dan zakat harta (zakat maal). Dalam ayat lain, Allah SWT berfirman dalam Al Qur'an (Surat Adz - Dzariat ayat 19) :

"Dan pada harta-harta mereka ada hak untuk orang miskin yang meminta dan orang miskin yang tidak mendapat bagian."

Karena membayar zakat hukumnya wajib bagi umat islam sebagai wujud taat kepada Rosul dan patuh kepada Allah SWT sesuai dengan firman Allah SWT diatas, sedangkan membayar pajak hukumnya wajib bagi seluruh warga Negara Indonesia sebagai rasa berbakti kepada Negara. Perusahaan yang memiliki harta sesuai dengan firman Allah SWT maka wajib melaksanakan rukun islam yang ke tiga dan wajib memenuhi tanggung jawabnya sebagai warga Negara Indonesia yang baik dengan taat membayar pajak.
Peraturan perpajakan menyebutkan bahwa zakat yang telah dibayar perusahaan melalui badan pengelola zakat yang telah disahkan oleh pemerintah maka tidak dikenakan pajak atau bukan merupakan objek pajak.Sehingga dapat menekan laba fiskal.

PT. Wonojati Wijoyo Kediri merupakan perusahaan manufaktur yang bergerak dibidang industry garden furniture.Manajemen perusahaan sudah melakukan perencanaan pajak dalam meminimalisir kewajiban pajak.Cara yang sudah pernah digunakan oleh perusahaan melalui penyusutan aktiva dan melakukan pendanaan pengadaan barang menggunakan jasa leasing atau sewa guna usaha.Namun perusahaan belum pernah menerapkan pembayaran zakat sebagai penghematan pajak.Selama ini perusahaan hanya melakukan sumbangan terhadap lingkungan sekitar pada saat hari besar saja.

Berdasarkan latar belakang diatas peneliti mencoba melakukan penelitian dengan judul "Tax Planning Melalui Penerapan Zakat Sebagai Upaya Meminimalisir Beban Pajak Badan"

\section{Tujuan Penelitian}

Tujuan dari penelitian ini untuk mengetahui tax planning melalui penerapan zakat sebagai upaya meminimalisir beban pajak badan.

\section{Manfaat Penelitian}

Dari hasil penelitian yang dilakukan diharapkan dapat memberi beberapa manfaat antara lain:

a. Manfaat Operasional.

Sebagai informasi yang dapat diperhatikan bagi manajemen pajakPT. Wonojati Wijoyo Kediri dalam melakukan perencanaan pajak.

b. Manfaat Akademik.

Hasil penelitian yang diperoleh bisa digunakan sebagai referensi perencanaan pajak bagi peneliti selanjutnya dan menambah wawasan, pengetahuan, serta 
meningkatkanpemahaman mengenai zakat harta.

\section{METODE PENELITIAN \\ Ruang Lingkup Penelitian}

Ruang lingkup dalam penelitian ini penulis mengkaji dalam bidang tax planningyang difokuskan pada masalah tentangtax planning melalui penerapan zakat sebagai upaya meminimalisir beban pajak badan pada tahun 2016

\section{Lokasi Penelitian}

Lokasi penelitian dilakukan di PT. Wonojati Wijoyo Kediri yang beralamat di jalan Mataram No. 1 Kediri. Alasan peneliti memilih PT. Wonojati Wijoyo Kediri sebagai objek penelitian karena pihak manajemen perusahaan sangat terbuka dalam memberikan informasi berkaitan dengan penelitian. Waktu penelitian mulai bulan April 2017 sampai dengan bulan Agustus 2017.

\section{Jenis Data dan Sumber Data \\ Jenis Data}

Jenis data yang akan dianalisis adalah sebagai berikut:

Jenis data yang digunakan dalam penelitian ini sebagai berikut :

a. Data Kualitatif

Datayang disajikan bukan dalam bentuk angka - angka. Berupa data hasil wawancara.Data Kualitatif.

b. Data Kuantitatif

Datayang disajikan dalam bentuk angka angka.Berupa data laporan keuangan Tahun 2016.

\section{Sumber Data}

Sumber data yang digunakan penulis dalam mengevaluasi untuk mendapatkan kesimpulan penelitian adalah data primer, yaitu berupa data tentang struktur organisasi perusahaan, data karyawan, sejarah perusahaan dan sistem perencanaan pajak yang telah diterapkan perusahaan, sedangkan data sekunder berupa data-data yang diperoleh dari berbagai literatur atau artikel yang berhubungan dengan penelitian.

\section{Teknik Pengumpulan Data}

a. Penelitian Pustaka

Teknik ini dimaksudkan untuk memperoleh data kepustakaan dengan cara mempelajari,mengkajidanmenela

ahliteratur yang berkaitan dengan masalah yang diteliti berupa buku, jurnal, makalah, maupun hasil pencarian di internet yang berkaitan dengan penelitian.

b. Wawancara

Wawancara dilakukan dengan bertanya jawab langsung dengan pihak yang berkompeten dalam penelitian ini yang dimaksud yaitu manajemen pajak. Topik wawancara terkait sistem perencanaan pajak yang telah diterapkan oleh perusahaan pada tahun 2016.

c. Dokumentasi dilakukan dengan mengumpulkan data - data dari perusahaan yang berkaitan dengan tax planning.

d. Studi Lapangan

Peneliti melakukan pengamatan langsung ke lokasi perusahaan untuk mengetahui proses pelaksanaan perencanaan pajak.

\section{Identifikasi Variabel}

Dalam penelitian ini variabel yang diteliti terdiri dari tiga macam, yaitu :
a. Tax Planning
b. Zakat
c. Beban Pajak Penghasilan

\section{Teknik Analisis Data}

Dalam penelitian ini, penulis menggunakan analisis diskriptif kualitatif yaitu membandingkan data yang terkumpul dari perusahaan dengan landasan teori sebagai bahan acuan dalam menganalisis.

Adapun langkah-langkahnya sebagai berikut: 
1. Mengevaluasi rekonsiliasi fiskal guna menghitung $\mathrm{PPh}$ Badan yang dilakukan perusahaan sebelum menerapkan perencanaan pajak melalui pembayaran zakat.

2. Menghitung besarnya zakat dengan formula dari Rumah Zakat sebagai berikut :Besar Zakat $=[$ (Modal diputar + Keuntungan + piutang yang dapat dicairkan) - (hutang + kerugian)] x 2,5\%

3. Melakukan perhitungan $\mathrm{PPh}$ Badan setelah menerapkan perencanaan pajak melalui pembayaran zakat.
4. Membandingkan $\mathrm{PPh}$ Badan yang terutang sebelum dengan setelah menerapkan perencanaan pajak melalui pembayaran zakat.

\section{HASIL PENELITIAN DAN PEMBAHASAN}

Hasil Penelitian

Laporan Keuangan Perusahaan Tahun 2016

Tabel 4.4

Neraca

Untuk Tahun yang berakhir Pada Tanggal 31 Desember 2016

\begin{tabular}{|c|c|c|c|c|c|}
\hline \multicolumn{3}{|l|}{ ASET } & \multicolumn{3}{|c|}{ LIABILITAS DAN EKUITAS } \\
\hline ASET LANCAR & & & LIABILITAS & & \\
\hline Kas & $52,500,950$ & & H. Dagang & $82,500,000$ & \\
\hline Piutang Dagang & $95,000,000$ & & H. Pph Psl 21 & 380,700 & \\
\hline Cadangan kerugian piutang & & & H. Pph Psl 23 & 600,000 & \\
\hline UM pph ps 22 & & & H. Pph Psl 25 & & \\
\hline UM pph ps 25 & $10,000,000$ & & H. Pph Psl 4 Ayat 2 & & \\
\hline PPN masukan & $4,250,000$ & & PPN Keluaran & $7,500,000$ & \\
\hline Persd. Brg. Jadi & $80,250,000$ & & TOTAL LIABILITAS & & $90,980,700$ \\
\hline TOTAL ASET LANCAR & & $242,000,950$ & & & \\
\hline ASET TETAP & & & EKUITAS & & \\
\hline Tanah & $2,000,000$ & & Modal Saham & $132,000,000$ & \\
\hline Gedung & $100,000,000$ & & Dividen & & \\
\hline Ak. Penyusutan Gedung & $(10,000,000)$ & & Saldo Laba & $198,520,250$ & \\
\hline Kendaraan & $80,000,000$ & & TOTAL EKUITAS & & $330,520,250$ \\
\hline Ak. Penyusutan Kendaraan & $(10,000,000)$ & & & & \\
\hline Inventaris Kantor & $20,000,000$ & & & & \\
\hline Ak. Penyusutan Inventaris Kantor & $(2,500,000)$ & & & & \\
\hline TOTAL ASET TETAP & & $179,500,000$ & & & \\
\hline JUMLAH ASET & & $421,500,950$ & JUMLAH LIABILITA & N EKUITAS & $421,500,950$ \\
\hline
\end{tabular}

Sumber: data primer diolah 
Tabel 4.5

Laporan Laba Rugi

Untuk Tahun yang berakhir Pada Tanggal 31 Desember 2016

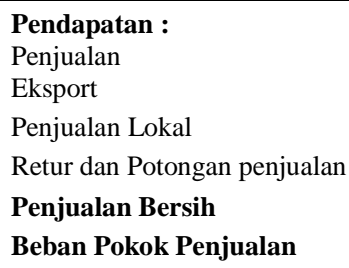

Sumber : data Primer diolah

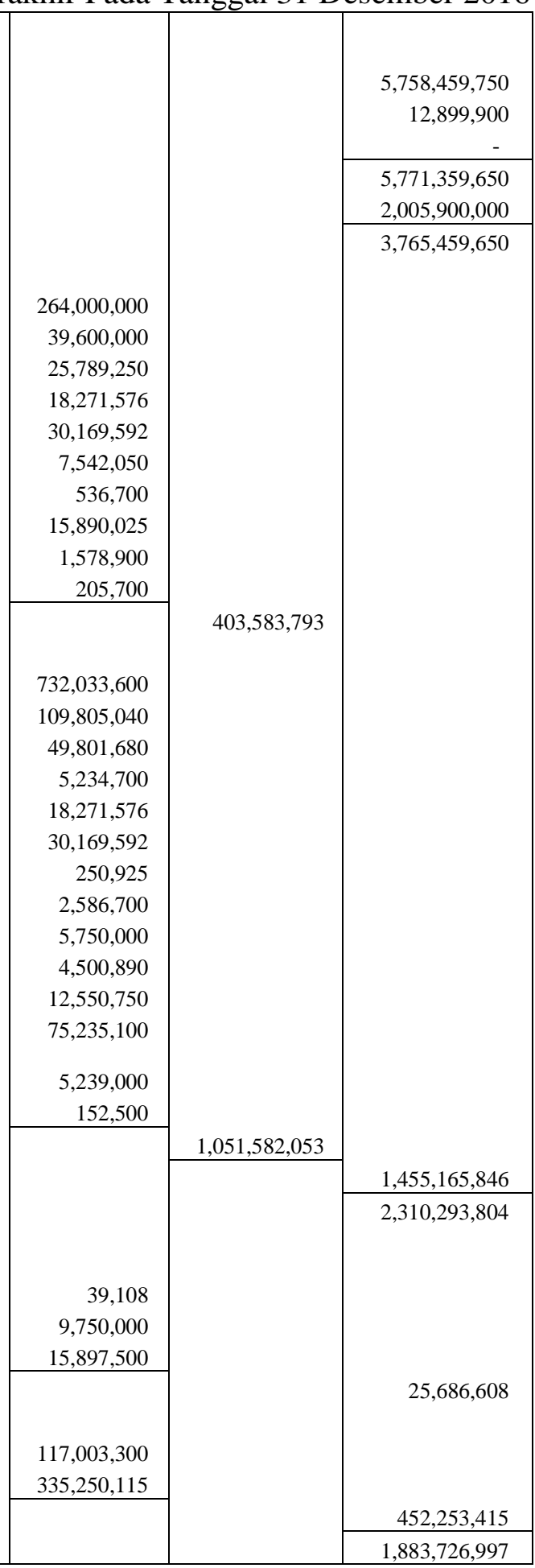


Pembahasan Hasil Penelitian

Mengevaluasi Rekonsiliasi Fiskal guna
menghitung Pph Badan Yang Dilakukan
Perusahaan Sebelum Menerapkan Perencanaan Pajak Melalui Pembayaran Zakat.

Tabel 4.6

Perhitungan PPh Badan Sebelum Melakukan Penerapan Perencanaan Pajak Melalui Pembayaran Zakat

\begin{tabular}{|c|c|c|c|c|c|c|}
\hline \multirow{2}{*}{\multicolumn{2}{|c|}{\begin{tabular}{|c|} 
Deskripsi \\
Peredaran Usaha
\end{tabular}}} & \multirow{2}{*}{ Komersial } & \multicolumn{2}{|c|}{ Koreksi Fiskal } & \multirow{2}{*}{ Fiskal } & \multirow{2}{*}{ Ket } \\
\hline & & & Positif & Negatif & & \\
\hline \multicolumn{7}{|l|}{ Pendapatan : } \\
\hline \multicolumn{2}{|l|}{ Penjualan Eksport } & $5,758,459,750$ & & & $5,758,459,750$ & \\
\hline \multirow{2}{*}{\multicolumn{2}{|c|}{$\begin{array}{l}\text { Penjualan Lokal } \\
\text { Retur dan Potongan } \\
\text { penjualan }\end{array}$}} & $12,899,900$ & & & $12,899,900$ & \\
\hline & & - & & & - & \\
\hline \multicolumn{2}{|l|}{ Penjualan Bersih } & $5,771,359,650$ & & & $5,771,359,650$ & \\
\hline \multicolumn{2}{|l|}{ Beban Pokok Penjualan } & $2,005,900,000$ & & & $2,005,900,000$ & \\
\hline \multicolumn{2}{|l|}{ Laba Kotor } & $\mathbf{3 , 7 6 5 , 4 5 9 , 6 5 0}$ & & & $3,765,459,650$ & \\
\hline \multicolumn{2}{|l|}{ Beban Penjualan: } & & & & - & \\
\hline \multirow{2}{*}{$\begin{array}{l}\text { Biaya Gajı } \\
\text { Biaya Tunjangan dan Bonus }\end{array}$} & Bag. Pemasaran & $264,000,000$ & & & $264,000,000$ & \\
\hline & Bag. Pemasaran & $39,600,000$ & $5,250,000$ & & $34,350,000$ & $\mathrm{a}$ \\
\hline Biaya Iklan dan Brosur & Bag. Pemasaran & $25,789,250$ & & & $25,789,250$ & \\
\hline Biaya Telephon dan Internet & Bag. Pemasaran & $18,271,576$ & & & $18,271,576$ & \\
\hline Biaya Listrik dan Air & Bag. Pemasaran & $30,169,592$ & & & $30,169,592$ & \\
\hline Biaya Pengiriman Barang & Bag. Pemasaran & $7,542,050$ & & & $7,542,050$ & \\
\hline Biaya Pengiriman Dokumen & Bag. Pemasaran & 536,700 & & & 536,700 & \\
\hline Biaya EMKL & Bag. Pemasaran & $15,890,025$ & & & $15,890,025$ & \\
\hline Biaya Dinas Luar & Bag. Pemasaran & $1,578,900$ & & & $1,578,900$ & \\
\hline \multirow{2}{*}{$\begin{array}{l}\text { Biaya Lain - lain } \\
\text { Total Beban Penjualan }\end{array}$} & Bag. Pemasaran & 205,700 & & & 205,700 & \\
\hline & & $403,583,793$ & & & $\mathbf{3 9 8 , 3 3 3 , 7 9 3}$ & \\
\hline \multicolumn{2}{|c|}{ Beban Administrasi dan Umum : } & & & & - & \\
\hline Biaya Gaji & Staff Kantor dan Direksi & $732,033,600$ & & & $732,033,600$ & \\
\hline \multirow{2}{*}{$\begin{array}{l}\text { Biaya Tunjangan dan Bonus } \\
\text { Biaya PPh Pasal } 21\end{array}$} & Staff Kantor dan Direksi & $109,805,040$ & $6,500,000$ & & $103,305,040$ & $\mathrm{~b}$ \\
\hline & & $49,801,680$ & & & $49,801,680$ & \\
\hline \multicolumn{2}{|c|}{ Biaya Pajak Daerah (PBB, Kir Kendaraan, dll) } & $5,234,700$ & & & $5,234,700$ & \\
\hline Biaya Telephon dan Internet & Staff Kantor dan Direksi & $18,271,576$ & & & $18,271,576$ & \\
\hline Biaya Listrik dan Air & Staff Kantor dan Direksi & $30,169,592$ & & & $30,169,592$ & \\
\hline Biaya Pengiriman Dokumen & Staff Kantor dan Direksi & 250,925 & & & 250,925 & \\
\hline Biaya Dinas Luar & Staff Kantor dan Direksi & $2,586,700$ & & & $2,586,700$ & \\
\hline Biaya Sewa & Staff Kantor dan Direksi & $5,750,000$ & $5,000,000$ & & 750,000 & $\mathrm{c}$ \\
\hline Biaya Asuransi & Staff Kantor dan Direksi & $4,500,890$ & $2,000,000$ & & $2,500,890$ & $\mathrm{~d}$ \\
\hline Biaya Jasa Pihak ke-Tiga & & $12,550,750$ & & & $12,550,750$ & \\
\hline Biaya Penyusutan Aktiva Tetap & & $75,235,100$ & $25,718,749$ & & $49,516,351$ & $\mathrm{e}$ \\
\hline Biaya Sumbangan & & $5,239,000$ & $5,239,000$ & & - & $\mathrm{f}$ \\
\hline Biaya Lain - lain & Staff Kantor dan Direksi & 152,500 & & & 152,500 & \\
\hline
\end{tabular}




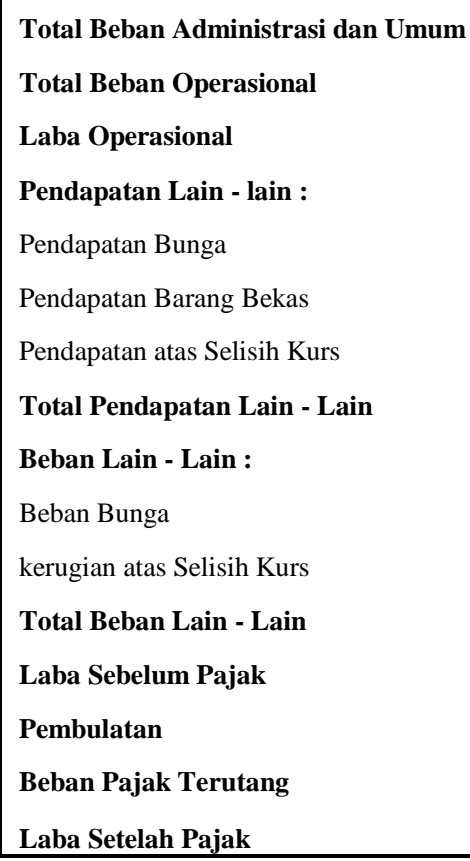

Sumber : Data Primer diolah

Berdasarkan tabel 4.6 Rekonsiliasi Fiskal yang telah dilakukan oleh PT Wonojati Wijoyo, Kediri sebagai dasar menghitung beban pajak terutang telah sesuai dengan undang - undang yang berlaku. Berikut keterangan mengenai rekonsiliasi fiskal diatas

a. Sesuai dengan pasal 9 (1) huruf e UU $\mathrm{PPh}$, biaya pemberian rekreasi dan pemberian susu kepada karyawan bagian penjualan termasuk penggantian atau imbalan sehubungan dengan pekerjaan atau jasa yang diberikan dalam bentuk natura dan kenikmatan yang tidak bisa dikurangkan dari penghasilan bruto.

b. Sesuai dengan pasal 9 (1) huruf e UU $\mathrm{PPh}$, biaya pemberian rekreasi dan pemberian susu kepada karyawan bagian administrasi dan umum termasuk penggantian atau imbalan sehubungan dengan pekerjaan atau jasa yang diberikan dalam bentuk natura dan kenikmatan yang tidak bisa dikurangkan dari penghasilan bruto.

c. Sesuai dengan pasal 9 (1) huruf e UU $\mathrm{PPh}$, biaya sewa rumah yang diperuntukan untuk tenaga kerja asing termasuk penggantian atau imbalan

\begin{tabular}{|c|c|c|}
\hline $1,051,582,053$ & $1,007,124,304$ & \\
\hline $1,455,165,846$ & $1,405,458,097$ & \\
\hline $2,310,293,804$ & $2,360,001,553$ & \\
\hline & - & \\
\hline 39,108 & 39,108 & \\
\hline $9,750,000$ & $9,750,000$ & \\
\hline $15,897,500$ & $15,897,500$ & \\
\hline $25,686,608$ & $25,686,608$ & \\
\hline & - & \\
\hline $117,003,300$ & $117,003,300$ & \\
\hline $335,250,115$ & $335,250,115$ & \\
\hline $452,253,415$ & $452,253,415$ & \\
\hline $1,883,726,997$ & $1,933,434,746$ & \\
\hline $1,883,726,000$ & $1,933,434,000$ & \\
\hline $275,096,375$ & $282,355,625$ & $\mathrm{~g}$ \\
\hline $1,608,629,625$ & $1,651,078,375$ & \\
\hline
\end{tabular}

sehubungan dengan pekerjaan atau jasa yang diberikan dalam bentuk natura dan kenikmatan yang tidak bisa dikurangkan dari penghasilan bruto.

d. Sesuai dengan pasal 9 (1) huruf i UU PPh, premi asuransi kecelakaan kerja untuk keluarga mantovani termasuk dalam pengertian biaya yang dibebankan atau dikeluarkan untuk kepentingan pribadi wajib pajak atau orang yang menjadi tanggungannya yang tidak bisa dikurangkan dari penghasilan bruto.

e. Sesuai dengan pasal $11 \mathrm{UU} \mathrm{PPh}$, terhadap asset yang termasuk kelompok I s.d kelompok I, wajib pajak diperkenankan memilih antara metode garis lurus atau metode saldo menurun. PT Wonojati Wijoyo, Kediri memilih menggunakan metode garis lurus namun terdapat perbedaan tariff penyusutan yang dipengaruhi oleh masa manfaat aktiva yang ditetapkan sesuai PSAK dengan UU Perpajakan tidak sama. Berikut ini hasil perhitungan penyusutan fiskal yang telah dihitung oleh perusahaan disajikan pada tabel 4.7 . 
Tabel 4.7

Koreksi Fiskal atas Biaya Penyusutan Aktiva

Tetap Tahun 2016

\begin{tabular}{|r|l|c|c|c|}
\hline \multirow{2}{*}{ No. } & \multirow{2}{*}{ Aktiva Tetap } & \multicolumn{2}{|c|}{ Beban Penyusutan } & \multirow{2}{*}{$\begin{array}{c}\text { koreksi } \\
\text { fiskal }\end{array}$} \\
\cline { 3 - 4 } & & Komersial & Fiskal & \\
\hline 1 & Gedung & $24,666,667$ & $18,750,000$ & $5,916,667$ \\
\hline 2 & mesin bag. Open & $4,166,666$ & $3,500,000$ & 666,666 \\
\hline 3 & mesin bag. Bandsaw & $9,333,333$ & $7,500,000$ & $1,833,333$ \\
\hline 4 & mesin bag. Moulding & $4,833,333$ & $3,750,000$ & $1,083,333$ \\
\hline 5 & mesin bag. Komponen & $4,833,333$ & $3,750,000$ & $1,083,333$ \\
\hline 6 & peralatan kantor & $28,666,667$ & $21,750,000$ & $6,916,667$ \\
\hline 7 & kendaraan & $17,000,000$ & $8,781,250$ & $8,218,750$ \\
\hline & Total & $\mathbf{9 3 , 4 9 9 , 9 9 9}$ & $\mathbf{6 7 , 7 8 1 , 2 5 0}$ & $\mathbf{2 5 , 7 1 8 , 7 4 9}$ \\
\hline
\end{tabular}

Sumber : Data Primer Diolah

f. Sesuai dengan pasal 4 ayat 3 UU PPh, terhadap bantuan atau sumbangan termasuk zakat yang diterima oleh badan amil zakat atau lembaga amil zakat yang dibentuk atau disahkan oleh pemerintah. Pada tahun 2016 perusahaan hanya melakukan sumbangan terhadap masyarakat sekitar dan sesuai dengan peraturan perpajakn tidak boleh di akui sebagai pengurang penghasilan.

g. Perhitungan Beban Pajak Penghasilan yang telah dilakukan oleh perusahaan sebagai berikut :

Pajak Penghasilan $=($ Penghasilan Bruto Biaya yang diperkenankan UU $\mathrm{PPh}$ ) $\mathrm{x}$ Tarif pasal 17

Peredaran Bruto perusahaan sebesar Rp 5.771.359.650,- karena kurang dari $\mathrm{Rp}$ 50.000.000.000 sehingga PT. Wonojati Wijoyo, Kediri mendapat fasilitas berupa pengurangan tariff sebesar 50\% yang dikenakan atas Penghasilan Kena Pajak dari bagian peredaran bruto sampai dengan Rp 4.800.000.000,-
1) Jumlah penghasilan kena pajak dari bagian penghasilan bruto yang memperoleh fasilitas :

$(\mathrm{Rp} \quad 4.800 .000 .000 \quad$ : $\quad \mathrm{Rp}$ 5.771.359.650) $\times \operatorname{Rp} 1.933 .434 .000=$ Rp 1.608.023.717,60 dibulatkan menjadi Rp 1.608.023.000

2) Jumlah penghasilan kena pajak dari bagian peredaran bruto yang tidak memperoleh fasilitas :

Rp 1.933.434.000 - Rp 1.608.023.000 $=\operatorname{Rp} 325.411 .000$

3) Jumlah pajak penghasilan terutang : $(50 \%$ x $25 \%) \times \mathrm{Rp} 1.608 .023 .000$

$$
\begin{array}{r}
=\operatorname{Rp} 201.002 .875 \\
25 \% x \operatorname{Rp} 325.411 .000=\operatorname{Rp} 81.352 .750 \\
=\operatorname{Rp} 282.355 .625
\end{array}
$$

Jadi selama tahun 2016 pajak penghasilan yang terutang oleh PT. Wonojati Wijoyo, Kediri sebelum melakukan penerapan perencanaan pajak melalui pembayaran zakat sebesar Rp 282.355.625,-sedangkan pajak yang terutang sebelum rekonsiliasi fiskal sebesar Rp 275.096.375,-Terdapat selisih sebesar Rp 7.259.250,-.

\section{Menghitung Besarnya Zakat}

Kadarnya zakat yang dibayar oleh PT. Wonojati Wijoyo, Kediri sebesar 2,5\%. Perhitungan besarnya zakat sebagai berikut : Besar Zakat $=[($ Modal diputar + Keuntungan + piutang yang dapat dicairkan) - (hutang + kerugian)] $\mathrm{x} 2,5 \%$

Besarnya Zakat $=(330.520 .250+$ $1.883 .726 .000+95.000 .000)-$ $(82.500 .000+335.250 .115) \times 25 \%$

$=1.891 .496 .135 \times 25 \%$

$=47.287 .403,38$ pembulatan 47.288.000,-

Jadi nilai zakat yang seharusnya dibayar oleh perusahaan sebesar Rp 47.288.000,-

Melakukan perhitungan PPh Badan setelah menerapkan perencanaan pajak melalui pembayaran zakat. 
Tabel. 4.8

Perhitungan PPh Badan Setelah Melakukan Penerapan Perencanaan Pajak Melalui Pembayaran Zakat

\begin{tabular}{|c|c|c|c|c|c|}
\hline \multirow{2}{*}{\multicolumn{2}{|c|}{$\begin{array}{cc}\text { Deskripsi } \\
\text { Peredaran Usaha } \\
\end{array}$}} & \multirow{2}{*}{ Komersial } & \multicolumn{2}{|c|}{ Koreksi Fiskal } & \multirow{2}{*}{ Fiskal } \\
\hline & & & Positif & Negatif & \\
\hline \multicolumn{6}{|l|}{ Pendapatan : } \\
\hline \multicolumn{2}{|l|}{ Penjualan Eksport } & $5,758,459,750$ & & & $5,758,459,750$ \\
\hline \multirow{2}{*}{\multicolumn{2}{|c|}{$\begin{array}{l}\text { Penjualan Lokal } \\
\text { Retur dan Potongan } \\
\text { penjualan }\end{array}$}} & $12,899,900$ & & & $12,899,900$ \\
\hline & & - & & & - \\
\hline \multicolumn{2}{|l|}{ Penjualan Bersih } & $5,771,359,650$ & & & $5,771,359,650$ \\
\hline \multicolumn{2}{|l|}{ Beban Pokok Penjualan } & $2,005,900,000$ & & & $2,005,900,000$ \\
\hline \multicolumn{2}{|l|}{ Laba Kotor } & $3,765,459,650$ & & & $3,765,459,650$ \\
\hline \multicolumn{2}{|l|}{ Beban Penjualan: } & & & & - \\
\hline \multicolumn{2}{|r|}{ Bag. Pemasaran } & $264,000,000$ & & & $264,000,000$ \\
\hline Biaya Tunjangan dan Bonus & Bag. Pemasaran & $39,600,000$ & $5,250,000$ & & $34,350,000$ \\
\hline & Bag. Pemasaran & $25,789,250$ & & & $25,789,250$ \\
\hline \multirow{2}{*}{ Biaya Telephon dan Internet } & Bag. Pemasaran & $18,271,576$ & & & $18,271,576$ \\
\hline & Bag. Pemasaran & $30,169,592$ & & & $30,169,592$ \\
\hline $\begin{array}{l}\text { Biaya Listrik dan Air } \\
\text { Biava Pengiriman Barang }\end{array}$ & Bag. Pemasaran & $7,542,050$ & & & $7,542,050$ \\
\hline $\begin{array}{l}\text { Biaya Pengiriman Barang } \\
\text { Biaya Pengiriman Dokumen }\end{array}$ & Biaya Pengiriman Dokumen & 536,700 & & & 536,700 \\
\hline Biaya EMKL & Bag. Pemasaran & $15,890,025$ & & & $15,890,025$ \\
\hline Biaya Dinas Luar & Bag. Pemasaran & $1,578,900$ & & & $1,578,900$ \\
\hline Biaya Lain - lain & Bag. Pemasaran & 205,700 & & & 205,700 \\
\hline \multicolumn{2}{|l|}{ Total Beban Penjualan } & $403,583,793$ & & & $398,333,793$ \\
\hline \multicolumn{2}{|c|}{ Beban Administrasi dan Umum : } & & & & - \\
\hline \multicolumn{2}{|r|}{ Staff Kantor dan Direksi } & $732,033,600$ & & & $732,033,600$ \\
\hline \multicolumn{2}{|c|}{ Biaya Tunjangan dan Bonus $\quad$ Staff Kantor dan Direksi } & $109,805,040$ & $6,500,000$ & & $103,305,040$ \\
\hline \multicolumn{2}{|l|}{ Biaya PPh Pasal 21} & $49,801,680$ & & & $49,801,680$ \\
\hline Biaya Pajak Daerah (PBB, Kir I & Kendaraan, dll) & $5,234,700$ & & & $5,234,700$ \\
\hline Biaya Telephon dan Internet & Staff Kantor dan Direksi & $18,271,576$ & & & $18,271,576$ \\
\hline Biaya Listrik dan Air & Staff Kantor dan Direksi & $30,169,592$ & & & $30,169,592$ \\
\hline Biaya Pengiriman Dokumen & Staff Kantor dan Direksi & 250,925 & & & 250,925 \\
\hline Biaya Dinas Luar & Staff Kantor dan Direksi & $2,586,700$ & & & $2,586,700$ \\
\hline Biaya Sewa & Staff Kantor dan Direksi & $5,750,000$ & $5,000,000$ & & 750,000 \\
\hline Biaya Asuransi & Staff Kantor dan Direksi & $4,500,890$ & $2,000,000$ & & $2,500,890$ \\
\hline Biaya Jasa Pihak ke-Tiga & & $12,550,750$ & & & $12,550,750$ \\
\hline Biaya Penyusutan Aktiva Tetap & & $75,235,100$ & $25,718,749$ & & $49,516,351$ \\
\hline Biaya Sumbangan & & $5,239,000$ & $5,239,000$ & & - \\
\hline Biaya Lain - lain & Staff Kantor dan Direksi & 152,500 & & & 152,500 \\
\hline Total Beban Administrasi dan & an Umum & $\mathbf{1 , 0 5 1 , 5 8 2 , 0 5 3}$ & & & $1,007,124,304$ \\
\hline Total Beban Operasional & & $\mathbf{1 , 4 5 5 , 1 6 5 , 8 4 6}$ & & & $1,405,458,097$ \\
\hline Laba Operasional & & 2,310,293,804 & & & $2,360,001,553$ \\
\hline Pendapatan Lain - lain : & & & & & - \\
\hline
\end{tabular}






Sumber : Data Primer Diolah

Berdasarkan Tabel 4.8 terlihat beban pajak terutang sebesar $\mathrm{Rp}$ 275.449.750,-. Nilai tersebut mengalami penurunan dari pajak terutang sebelumnya yaitu sebesar $\mathrm{Rp}$ 282.355.625,- karena dipengaruhi oleh zakat yang telah dibayar oleh perusahaan sebesar Rp 47.288.000,--. Berikut Perhitungan PPh Badan setelah melakukan perencanaan pajak melalui penerapan zakat :

a. Jumlah penghasilan kena pajak dari bagian penghasilan bruto yang memperoleh fasilitas :

$(\operatorname{Rp} 4.800 .000 .000: \operatorname{Rp} 5.771 .359 .650) \mathrm{x}$ $\mathrm{Rp}$ 1.886.146.000 =Rp 1.568.694.614,28 dibulatkan menjadi Rp 1.568.694.000

b. Jumlah penghasilan kena pajak dari bagian peredaran bruto yang tidak memperoleh fasilitas :

Rp 1.886.146.000 - Rp 1.568.694.000 = Rp 317.452.000

c. Jumlah pajak penghasilan terutang :

(50\% x 25\%) x Rp 1.568.694.000 $=\operatorname{Rp} 196.086 .750$

$25 \% \times \operatorname{Rp} 317.452 .000=\mathrm{Rp} \quad 79.363 .000$ $=\overline{\mathrm{Rp} 275.449 .750}$

Jadi selama tahun 2016 pajak penghasilan yang terutang oleh PT. Wonojati Wijoyo, Kediri setelah melakukan penerapan

\begin{tabular}{|c|c|}
\hline 39,108 & 39,108 \\
\hline $9,750,000$ & $9,750,000$ \\
\hline $15,897,500$ & $15,897,500$ \\
\hline \multirow[t]{2}{*}{$25,686,608$} & $25,686,608$ \\
\hline & - \\
\hline $117,003,300$ & $117,003,300$ \\
\hline $335,250,115$ & $335,250,115$ \\
\hline $452,253,415$ & $452,253,415$ \\
\hline $\mathbf{1 , 8 8 3 , 7 2 6 , 9 9 7}$ & $1,933,434,746$ \\
\hline \multirow[t]{4}{*}{$\mathbf{1 , 8 8 3 , 7 2 6 , 0 0 0}$} & $1,933,434,000$ \\
\hline & $47,288,000$ \\
\hline & $\mathbf{1 , 8 8 6 , 1 4 6 , 0 0 0}$ \\
\hline & $\mathbf{1 , 8 8 6 , 1 4 6 , 0 0 0}$ \\
\hline $275,096,375$ & $275,449,750$ \\
\hline $1,608,629,625$ & $1,610,696,250$ \\
\hline
\end{tabular}

zakat sebesar Rp 275.449.750,- dan pajak yang terutang sebelum rekonsiliasi fiskal sebesar Rp 275.096.375,-. Terdapat selisih sebesar Rp 353.375,-.

Membandingkan PPh Badan yang terutang sebelum dengan setelah menerapkan perencanaan pajak melalui pembayaran zakat.

Perbandingan beban pajak penghasilan yang terutang oleh PT. Wonojati Wijoyo, Kediri pada tahun 2016 sebelum melakukan penerapan perencanaan pajak melalui pembayaran zakat sebesar $\mathrm{Rp}$ 282.355.625,- sedangkan setelah melakukan penerapan zakat sebesar Rp 275.449.750,selisihnya sebesar Rp 6.905.875,- dan pajak yang terutang sebelum rekonsiliasi fiskal sebesar Rp 275.096.375,-. Terdapat selisih sebesar Rp 353.375,-. Sehingga perusahaan mampu melakukan penghematan pajak sebesar Rp 6.905.875,--

\section{KESIMPULAN DAN SARAN Kesimpulan}

Dari hasil penelitian yang peneliti lakukan di PT. Wonojati Wijoyo, serta berdasarkan hasil pembahasan, maka dapat ditarik kesimpulan sebagai berikut :

1. Hasil rekonsiliasi fiskal guna menghitung pph badan yang dilakukan perusahaan 
sebelum menerapkan perencanaan pajak melalui pembayaran zakat sebesar Rp 282.355.625,-

2. Kadarnya zakat yang dibayar oleh perusahaan menggunakan tarif 2,5\%. Besarnya zakat yang diusulkan oleh peneliti senilai Rp 47.288.000,-

3. Hasil perhitungan $\mathrm{PPh}$ Badan setelah menerapkan perencanaan pajak melalui pembayaran zakat sebesar Rp 275.449.750,-

4. Hasil perbandingan antara perhitungan PPh Badan yang terutang sebelum dengan setelah menerapkan perencanaan pajak melalui pembayaran zakat yaitu terdapat selisih sebesar Rp 6.905.875,- dan pajak yang terutang sebelum rekonsiliasi fiskal sebesar Rp 275.096.375,-. sehingga selisih antara perhitungan setelah penerapan pajak dengan sebelum rekonsiliasi fiskal sangat sedikit yaitu sebesar Rp 353.375,-.

\section{Saran}

Disini peneliti mencoba memberikan rekomendasi dengan harapan dapat memberi manfaat bagi PT. Wonojati Wijoyo, dalam memenuhi kewajibannya sebagai wajib pajak badan dapat lebih efektif. Saran - saran yang diberikan antara lain :

a. Sebaiknya rekonsiliasi fiskal yang dilakukan sesuai dengan peraturan perpajakan terbaru.

b. Sebaiknya manajemen perusahaan meninjau ulang perencanaan pajak yang telah dilakukan dengan mempertimbangkan penerapan pembayaran zakat sebesar $2,5 \%$ dari laba usaha sebelum pajak.

c. Sebaiknya zakat yang hendak dibayar melalui badan amil zakat atau lembaga amil zakat yang telah disahkan oleh pemerintah. Karena dapat diakui sebagai pengurang pajak tanpa harus dikoreksi fiskal.

d. Sebaiknya zakat perusahaan wajib dibayar setiap laba atau keuntungan perusahaan telah mencapai nisab. Karena membayar zakat selain mampu mensucikan harta juga merupakan perintah Allah SWT sesuai dengan firman-NYA dalam AlQuran.

\section{DAFTAR PUSTAKA}

Al Qur'an Surat An Nur (ayat 24-25)

- Surat Adz - Dzariat (ayat 19)

Ali, Nuruddin Muhammad, (2006). Zakat, sebagai Instrumen dalam Kebijakan Fiskal, Jakarta : PT Raja Grafindo Persada

Ashar. Pajak dan Zakat : Suatu Kajian Komparatif. FENOMENA, Volume V, No. 2, 2013. STAIN Samarinda

Cahyono, Aris Tri dan Erdania Eka Putri.Penerapan Zakat Sebagai Perencanaan Pajak UntukEfisiensi Pph Badan Pada PT. Alwan Zahira Samarinda .JURNAL EKSIS Vol.8 No.1, Mar 2012: 2001 - 2181.ISSN : 02166437. Jurusan Akuntansi Politeknik Negeri Semarang.

Gurning, Herfita Rizki Hasanah dan Haroni doli hamoraon ritonga. Analisis Tingkat Kesadaran Masyarakat Kecamatan Medan Baru Dalam Membayar Zakat. Jurnal Ekonomi dan Keuangan Vol.3 No.7.

https://www.cermati.com/artikel/jenis-zakatyang-mesti-anda-keluarkan-dan-rumusmenghitungnya. diakses pada tanggal 6 Mei 2017.

https://www.rumahzakat.org/dalil-zakatprofesi/diakses pada tanggal 6 mei 2017.

Mardiasmo, (2016). Perpajakan. Edisi Terbaru 2016, Yogyakarta : Andi.

Martani, Dwi. (2015). Akuntansi Keuangan Menengah Berbasis PSAK. Buku 2, Jakarta Selatan : Salemba Empat.

Muljono, Djoko dan Baruni Wicaksono.(2009). Akuntansi Pajak Lanjutan. Yogyakarta: Andi Offset.

Muttaqien, Ma'ruf. (2015). Ternyata Zakat Itu Hebat, Jakarta Pusat : LazizMu.

Norvadewi \& Akhmad Nur Zaroni, (2009), Pendayagunaan Zakat Produktif di 
Lembaga Zakat dan Pengaruhnya terhadap Peningkatan Usaha Ekonomi Umat (Studi Komparatif diBAZ Propinsi Kaltim dan LAZ DPU Kaltim), Hasil Penelitian, Samarinda, P3M Stain Samarinda.

Purwono, Herry.(2010). Dasar-Dasar Perpajakan dan Akuntansi Pajak.Yogyakarta : Erlangga.

Resmi, Siti. (2014), Perpajakan Teori Dan Kasus, Edisi Kedelapan, Buku Satu, Jakarta : Salemba Empat.

Sanusi, Anwar. (2015), Metode Penelitian Bisnis, Jakarta : Salemba Empat.

Soekrisno, Agoes Dan Erlita. (2014), Akuntansi Perpajakan, Edisi Kedua, Jakarta : Salemba Empat.

Suandy, Erly (2009). Perencanaan Pajak, Edisi Keempat, Jakarta : Salemba Empat.

Supramono dan Theresia Woro Damayanti. (2010). Perpajakan Indonesia Mekanisme dan Perhitungan,Yogyakarta : Andi Offset.

Undang - undang republik indonesia nomor 36 tahun 2008 tentang perubahan keempat atas undang-undang nomor 7 tahun 1983 tentang pajak penghasilan

Waluyo (2013), Perpajakan Indonesia, Edisi Kesebelas, Jakarta : Salemba Empat.

Warren, Carl S. dkk.(2016), Pengantar Akuntansi Adaptasi Indonesia. Edisi 25.Jakarta : Salemba Empat 